\title{
Staging of Lung Cancer to Rule Out Progression
}

National Cancer Institute

\section{Source}

National Cancer Institute. Staging of Lung Cancer to Rule Out Progression. NCI

Thesaurus. Code C137877.

Staging of lung cancer using invasive and/or imaging modalities to assess progression of disease. 